\title{
The Analysis of Bullwhip Effect in Supply Chain Based on Strategic Alliance
}

\author{
Rui Xu, Xiaoli Li, Xiaomin Song, Gang Liu \\ School of Business, Hubei University, Wuhan, 430062, P. R. China, \\ wdxj826@126.com
}

\begin{abstract}
Bullwhip effect is a widespread and serious probiem in supply chain management, both domestic and foreign scholars studied and came to a conclusion consistently: That the main functions that cause bullwhip effect are need forecasts, batches ordering, and fluctuations in price, rational decisionmaking, and time deferment and in coordination, supply chain structure. Many scholars have done quantifying study on bullwhip effect, but no one has think of the element that the ordering enterprises may magnify their demand and calculated the effect in the whole supply chain. This paper leads into the magnifying rate of market demand based on the research of Lee and Chen and others, quantifying the overstock caused by bullwhip effect in the whole supply chain, and contrast the condition under strategic alliance pattern and the condition under non-strategic alliance pattern, then testified the first pattern can bring benefits to enterprises and it is useful for saving resources, which can serve as good apocalypse for managers and entrepreneurs in supply chain.
\end{abstract}

\section{Introduction}

Supply chain management has being paid close attention to both by the theory boundary and the business circles. As the most important function index sign in supply chain structure and the most important performance index sign in the operation of supply chain bullwhip effect becomes the hot to be studied. It refers to the phenomenon that ultimate marketplace demand is enlarged increasingly in the process of transferring along supply chain toward the upper enterprises from the retail dealer. It was first bring about by Forrester(1958) [1] in "industrial dynamics", he listed a series of bullwhip effect examples in one book, in his opinion, bullwhip effect is caused by the constant change of organization behavior. Bullwhip effect leads to a manufacture making a production plan wrongly, enlarging stock investment, cutting down profits, reducing the standard of service, thereby brings catastrophic consequence to enterprises, many domestic and foreign scholars have done large amount of research on the cause and how to removes bullwhip effect. The

Please use the following format when citing this chapter:

Xu, R., Li, X., Song, X., Liu, G., 2007, in IrlP International Federation for Information Processing, Volume 251, Integration and Innovation Orient to E-Socicty Volumel, Wang, W. (Eds), (Boston: Springer), pp. 452-458. 
mainly studying concentrates on the existence, the quantifying, the weakening, and the control of bullwhip effect.

For the weakening and controlling of bullwhip effect, the first step is to find out the cause and the second step is to quantify bullwhip effect. For the first step, domestic and foreign scholars found out seven functions such as demand forecasting, batches ordering, fluctuations of price, rational decision -making, time deferment and incoordination, and supply chain structure.

For the second step, there are many analysis. Wan(2002) [2] discussed the impacts of suppliers' assignment over bullwhip effect. $\mathrm{Lu}(2002)$ [3] certificated that the fluctuations in price or suppliers' shortsighted making price would lead to bullwhip effect. Chen adopted different forecasting technologies. At the same time, Chen(2000) [4] certificated that information share can diminish bullwhip effect efficiently, but can not eliminate bullwhip effect completely. And Chen(2000) [5] adopted the exponent level and smooth law to calculate, analysis the bullwhip effect in the two kinds of demanding patterns, and contrasted the results. Graves, Alwan and $\mathrm{Li}$ used time series analysis for bullwhip effect studying. Graves(1999) [6] had done this: calculated bullwhip effect when using an exponential smoothing forecast and adaptive base-stock, under the $\operatorname{ARIMA}(0,1,1)$ pattern which means unsteady demanding. Alwan(2003) [7] proved that under the AR(1) demanding pattern, using optimum forecasting method and $(\mathrm{s}, \mathrm{S})$ strategy, bullwhip effect will not happen when the neighbor term demand are negatively related. Li(2004) [8] expanded the research from peculiar time series two stage model to general $\operatorname{ARIMA}(0,1,1)$ time series many stage models, brought forward and proved that anti-bullwhip effect exists.

Their study mainly concentrates on three methods, such as system dynamics model taking Forrester(1958) [1] as a representative, autoregressive model taking Chen(2000) [4] as a representative, and Kalman filter model [9].

These study all concentrates bullwhip effect on suppliers, and have not think about the factor of demand and supply when models. For these disadvantages, this article builds a new model when leading into a market demand exaggerate rate and basing on Lee's (1997) [10] model and hypothesis. Besides, this article quantifies and contrasts the bullwhip effect under strategic alliance model and non-strategic alliance model from the whole supply chain. As a result, it proves that strategic alliance model can bring benefits to all the enterprises in supply chain.

\section{The Quantifying Analysis of Lee et al}

(1) Assumes in a two stage supply chain there is one supplier and i retail dealers ( $\mathrm{i}=$ $1,2, \ldots, \mathrm{n})$, retail dealers' demands area AR(1) models follow:

$$
D_{i t}=d+\rho D_{i t-1}+\pi_{i t}
$$

Among the express $d$ represents a constant, $d>0 ; \rho$ expresses the relevance modulus, $-1<\rho<1 ; D_{i t}$ expresses the forecasting demand of retail dealer $i$ at the stage $t$; $\pi_{i t}$ expresses a random variable obeying $\left(0, \sigma^{2}\right)$ lognormal distribution.

(2) Assumes that the retail dealers and supplier do not share information, in the condition, all the enterprises forecast their market demand independently and retail dealers adopt $(\mathrm{s}, \mathrm{S})$ ordering tactics which means that when the stock is lower than 
the value $s$, makes stock increase to $S$ level by ordering goods. $s$ means the ordering point, $\mathrm{S}$ means the maximal stock. Assume again that the retail dealers do not have fixed cost when ordering goods from the manufacturer, then $s=S$. Each retail dealer's target ordering level $\mathrm{S}_{\mathrm{it}}$ expresses as follow:

$$
S_{i t}=m_{i l}+k \sigma \sqrt{v}
$$

Among the express, $m_{i t}$ indicates the condition mean number, $\sigma$ indicates the condition variance, and $p$ indicates cost of being out of stock; $h$ indicates stock cost; 1 indicates lead time, then:

$$
\begin{aligned}
& m_{i t}=\frac{d}{1-p}\left\{(l+1)-\sum_{j=1}^{l+1} \rho^{j}\right\}+\frac{\rho\left(1-\rho^{l+1}\right)}{1-\rho} D_{i t} \\
& v=\frac{1}{(1-\rho)^{2}} \sum_{j=1}^{l+1}\left(1-\rho^{j}\right)^{2} \\
& k=\phi^{-1\left(\frac{p}{p+h}\right)}
\end{aligned}
$$

According to hypothesis (1), suppliers' demand forecasting is:

$Y_{i t}=D_{i t}+\left(S_{i t}-S_{i t-1}\right)$

Put expression (2) into expression (6) to get:

$Y_{i t}=D_{i t}+\left(m_{i t}-m_{i t-1}\right)$

Put expression (3) into expression (7) to get:

$$
Y_{i t}=D_{i t}+\frac{\rho\left(1-\rho^{l+1}\right)}{1-\rho}\left(D_{i t}-D_{i t-1}\right)
$$

Put expression (1) into expression (8) to get:

$$
Y_{i t}=\frac{\left(1-\rho^{l+2}\right) d}{1-\rho}+\rho^{l+2} D_{i t-1}+\frac{\left(1-\rho^{l+2}\right)}{1-\rho} \pi_{i t}
$$

\section{The Model of this article}

(1) Assumes that the factual demand during $t+1$ term is $A_{t+1}$;

(2) Assume that at the end of $t+1$ term the backlog of excess demand is $B_{t+1}$.

\subsection{The Market Backlog of Excess Demand in Supply Chain under Non- strategic Alliance Model}

Under this model, there is no information share, every retail dealer forecasts demand and send out their orders to the supplier independently. Since the uncertainty of marketplace, sometimes demand is greater than supplies in the whole market, and then a rational supplier often distributes a fixed rate of the each retail dealer's order. Assume retail dealer $\mathrm{i}$ forecasts that the supplying rate according to his order is $\alpha_{i}$ (which is a constant), then he will exaggerate his order by $1 / \alpha_{i}$ times. Assumes that 
every retail dealer want to get the full amount of their forecasting demand, then they order will be:

$$
D_{i t}^{\prime}=\frac{D_{i t}}{\alpha_{i}} \quad\left(0<\alpha_{i} \leq 1\right)
$$

Because of the insharing of information, each supplier has to predicts the demands of every retailer according to their orders during the last term. So revise (9) with (10) to get supplier's demand forecasting for each retail dealer during term $t$ is:

$$
Y_{i t}=\frac{\left(1-\rho^{l+2}\right) d}{1-\rho}+\rho^{l+2} \frac{D_{i t-1}}{\alpha_{i}}+\frac{\left(1-\rho^{l+2}\right)}{1-\rho} \pi_{i t}
$$

The supplier's overall demand forecasting for every retail dealer during term $t+1$ is the total of supplier's demand forecasting for each retail dealer during term $t+1$ just as follow:

$$
Y_{t+1}=\sum_{i=1}^{n} Y_{i t+1}
$$

Put expression (11) into expression (12) to get:

$$
Y_{t+1}=\frac{\left(1-\rho^{l+2}\right) n d}{1-\rho}+\rho^{l+2} \sum_{i=1}^{n} \frac{D_{i t}}{\alpha_{i}}+\frac{\left(1-\rho^{l+2}\right)}{1-\rho} \sum_{i=1}^{n} \pi_{i t+1}
$$

At the end of term $t+1$, the total backlog of excess demand in the supply chain is the total demand forecasting Subtract the actual demand during the term just as follow:

$$
B_{t+1}=Y_{t+1}-A_{t+1}
$$

Put expression (13) into expression (14) to get:

$$
B_{t+1}=\frac{\left(1-\rho^{l+2}\right) n d}{1-\rho}+\rho^{l+2} \sum_{i=1}^{n} \frac{D_{i t}}{\alpha_{i}}+\frac{\left(1-\rho^{i+2}\right)}{1-\rho} \pi_{i t+1}-A_{t+1}
$$

\subsection{The Market Backlog of Excess Demand in Supply Chain under Strategic Alliance Model}

Under this pattern, all retail dealers and suppliers form a strategic alliance, sharing information, trusting each other, and wielding Third-party logistics enterprises such as the distribution center for united tock and distribution.

In this condition, only supplier has to forecast the whole market demand according to the actual market information from the retail dealers. Assume that the forecasting is a $\operatorname{AR}(1)$ model, which has been proved right by expression (9), and the forecasting model is:

$$
\begin{aligned}
& Y_{t+1}^{\prime}=d_{n}+\rho_{n} D_{t}+\delta_{t} \\
& D_{t}=\sum_{i=1}^{n} D_{i t}
\end{aligned}
$$

Among the express, $d_{n}$ is a constant, $d n>0 ; \rho_{n}$ is the relevance modulus, $-1<\rho_{n}<1$; $\delta_{\mathrm{it}}$ is a random variable obeying $\left(0, \varepsilon^{2}\right)$ lognormal distribution. 
Put expression (17) into expression (16) to get:

$$
Y_{t+1}^{\prime}=d_{n}+\rho_{n} \sum_{i=1}^{n} D_{i t}+\delta_{t}
$$

For both express (9) and express (18) are supplier's total demand forecasting for all retail dealers, and they are both $\mathrm{AR}(1)$ models, we can assume that they have equal relevance modulus, this means:

$$
\rho_{n}=\rho^{l+2}
$$

Since the marketplace facing the supplier under strategic alliance pattern is just the whole marketplace facing the retail dealers, it can be assumed that:

$$
\delta_{t}=\sum_{i=1}^{n} \pi_{i t}
$$

Then under this model, at the end of term $t+1$, the total backlog of excess demand in the supply chain is:

$$
B_{t+1}^{\prime}=Y_{t+1}^{\prime}-A_{t+1}
$$

Contrasting (12) and (15) to get:

$$
C_{t+1}=B_{t+1}-B_{t+1}^{\prime}
$$

$\left(C_{t+1}\right.$ is the cutting down amounts of backlog of excess demand or stock in supply chain because of strategic alliances.)

Put expression (14) and (20) into expression (22) to get:

$C_{t+1}=Y_{t+1}-Y_{t+1}^{\prime}$

Put expression (13), (18), (19) and (20) into expression (23) to get:

$$
C_{t+i}=\left(\frac{1-\rho^{l+2}}{1-\rho} n d-d_{n}\right)+\sum_{i=1}^{n}\left(\frac{1}{\alpha_{i}}-1\right) \rho_{n} D_{i t}+\left(\frac{1-\rho^{l+2}}{1-\rho}-1\right) \sum_{i=1}^{n} \pi_{i t+1}
$$

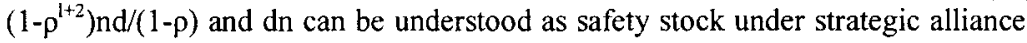
situation, it can be understood as that supplier only have one retail dealer or he can use any retail dealer's safety stock to meet other retail dealer's access demand, then synergy effect of strategic alliance model happens, and the total safety stock must be reduced, which means:

$$
d_{n} \leq n d
$$

For:

$\frac{1-\rho^{l+2}}{1-\rho}=1+\rho+\rho^{2}+\cdots+\rho^{l+1}$

So:

$$
\frac{1-\rho^{l+2}}{1-\rho} n d>n d>d_{n}
$$

Then we can get:

$$
\frac{1-\rho^{l+2}}{1-\rho} n d-d_{n}
$$


For $0<\alpha_{\mathrm{i}} \leq 1$, so:

$$
\sum_{i=1}^{n}\left(\frac{1}{\alpha_{i}}-1\right) \rho_{n} D_{i t} \geq 0
$$

For:

$$
\frac{1-\rho^{l+2}}{1-\rho}-1=\rho+\rho^{2}+\cdots+\rho^{l+1}
$$

So:

$$
\left(\frac{1-\rho^{l+2}}{1-\rho}-1\right) \sum_{i=1}^{n} \pi_{i t+1}>0
$$

According to (28), (29), (31), $\mathrm{C}_{\mathrm{t}+1} \geq 0$

\section{Conclusions}

\subsection{The Advantages of This Article's Model}

(1) Different industries are confronted with different market supply and demand situations; even the same industry is confronted with different market supply and demand situations at different terms. The main reason of bullwhip effect is the dissymmetry of information, and the most obvious action for retails dealer is to magnify their demands. But the past scholars didn't think of this element. For this, this article's model leads into a marketplace exaggerate rate $1 / \alpha_{i}\left(0<\alpha_{i} \leq 1\right)$, when $0<\alpha_{\mathrm{i}}<1$ it indicates that the market demand is greater than supplies, down-stream enterprises exaggerates their order when sending out order to the supplier; when $\alpha_{i}$ $=1$, it indicates a normal buyer's market. So this article's model perfects Lee (1997) [10] and Chen(2000) [5] and others model and it is representive, it can be broadly used in different industries and enterprises, it can be used in different market conditions and has better adaptability in today's changing market.

(2) The former models all concentrates bullwhip effect on suppliers, in fact, the reduce of bullwhip effect can save the resource of the whole society, then get benefits for every enterprise in supply chain, from this point, bullwhip effect has bad effects to all enterprises in supply chain, and the past models themselves are not easy for further studies of bullwhip effect in multi-level supply chain. This article's model standing in the point of the whole supply chain, calculate the backlog of excess demand in supply chain directly, and calculate the economic benefits (resource savings) from strategic alliance model, giving the managers of supply chain a direct express and serving as a basic basis for further distribution of the benefits among all the enterprises in supply chain.

(3)The article has discussed the improvement of backlog of excess demand in supply chain by the strategic alliances model, at the same time, in the model of this article, as long as that the forecasting demands of both the most down-stream enterprise and most upstream enterprise are known, then the backlog of excess demand in the whole supply chain is able to be got. Because of these, this article's 
model is more simplified and easy to carry out studies of bullwhip effect in multilevel supply chain.

\subsection{The Disadvantages of This Article's Model}

The deficiency of this article's model is that it does not think about the effect on orders from the backlog of excess demand during, and only concentrates on the disproportion of supply and demand during a give term.

Contrasting the advantages and the disadvantage, it is obvious that this article's model is better than the farmer's models. It breaks up the limitation that only concentrates the effect on supplier, adding the magnifying element, it perfects the past models, it is innovation, it makes the model have a wider use, and supplies a new angle of view to study bullwhip effect for the later scholars, it serves good apocalypse for managers and entrepreneurs in supply chain.

\section{Acknowledgments}

This research has been supported by the key projects of bureau of science and technology of Wuhan under Grant 20064003113-31 and education department of Hubei Province under Grant 2006y073.

\section{References}

73. 1. J.W. Forrester, Industrial Dynamics, Harvard Business Review 36(4), 37-66 (1958).

74. 2. J. Wan, M.Q. Li, J.S. Kou, Impact of Capacity Allocation on Bullwhip Effect in Supply Chain, Journal of Systems Engineering 17(4), 340-348 (2002). (in Chinese)

75. 3. G.B. Lu, Q.Y. Hu, X.B. Gan, Research on Combined Pricing and Inventory Strategy, Journal of Systems Engineering 17(6), 531-536 (2002). (in Chinese)

76. 4. F. Chen, Z. Drezner, J.K. Ryan, D. Simchi-Levi, Quantifying the Bullwhip Effect in a Simple Supply Chain: The Impact of Forecasting, Lead Times, and Information, Management Science 46(3), 436-443 (2000).

77. 5. F. Chen, J.K. Ryan, D. Simchi-Levi, the Impact of Exponential Smoothing Forecasts on the Bullwhip Effect, Naval Research Logistics 47(4), 269-286 (2000).

78. 6. Graves, C. Stephen, A Single-item Inventory Model for a Non-stationary Demand Process, Manufacturing \& Service Operations Management 1(1), 50-61 (1999).

79. 7. Alwan, C. Layth, Liu, J. John, D.Q. Yao, Stochastic Characterization of Upstream Demand Processes in a Supply Chain, IIE Transactions 35(3), 207-219 (2003).

80. 8. G. Li, S.Y. Wang, G. Yu, H. Yan, Bullwhip Effect and Validity of Production-smoothing Model, Journal of Management Sciences in China 7(1), 1-18 (2004). (In Chinese)

81. 9. X. Li, Y.S. Chen, How to Control the Bullwhip Effect Based on Systematic Structure Improvement, Logistics Technology (10), 58-60 (2006). (In Chinese)

82. 10. H.L. Lee, V. Padmanabhan, Information Distortion in a Supply Chain: The Bullwhip Effect, Management Science 43(4), 546-558 (1997). 